\title{
Ectopic cutaneous schistosomiasis - Case report
}

\author{
Lívia de Souza Mota ${ }^{1}$ \\ Fabiana Carvalho de Almeida ${ }^{1}$ \\ Renata Dórea Leal Teixeira ${ }^{1}$
}

\author{
Samuel Freire de Silva ${ }^{1}$ \\ Ludmila de Sousa Ursino Mesquita ${ }^{1}$ \\ Aline Miranda Soares ${ }^{2}$
}

DOI: http://dx.doi.org/10.1590/abd1806-4841.20142967

Abstract: Schistosomiasis is best known in its visceral form but it can attack the skin, its ectopic cutaneous man-
ifestation being rare and clinically difficult to diagnose. It is characterized by isolated or coalescent papules, ery-
thematous, pruritic or asymptomatic, with zosteriform distribution, often located on the trunk. The authors
report a case of a 28-year-old female patient with lesions on the abdomen, with positive stool results for
Schistosoma and absence of active symptoms of visceral disease. The case reveals rare exuberant cutaneous man-
ifestation and the importance of the diagnosis of this entity in patients from endemic regions. Keywords: Epidemiology; Parasitic diseases; Schistosomiasis; Skin

\section{INTRODUCTION}

Schistosomiasis is a systemic disease caused by a trematode of the Schistosoma genus, acquired when in contact with contaminated water. In the majority of cases, the infection is asymptomatic and, when present, gastrointestinal manifestations are the most frequently found. ${ }^{1}$

Cutaneous lesions caused by this trematode may be early, like cercarial dermatitis and urticaria, or late, like schistosomal chronic prurigo and cutaneous schistosomiasis (external genital, paragenital and ectopic forms). ${ }^{2}$ The most common cutaneous form is the one located in the anogenital region and few extragenital cases have been described, mainly because they are away from the regions irrigated by venous circuit contiguous to the usual location of the worms. ${ }^{3}$ Thus, they can be located in any part of the tegument, being more frequent on the trunk, especially on the thorax and abdomen. ${ }^{4}$

\section{CASE REPORT}

A 28-year-old female patient, phototype II, rural worker, born and originating from Itabaianinha$\mathrm{SE}$, presented at the dermatology service with complaints of multiple papular, erythematous and pruriginous lesions on the abdomen for 2 months. She denied other symptoms. She reported frequent baths in rivers.
At the physical examination were found round papules measuring about $3 \mathrm{~mm}$ in diameter, erythematous, confluent, some of them forming plaques, giving a zosteriform aspect to the lesions, affecting the abdominal region (epigastrium, mesogastrium and left upper quadrant) (Figures 1 and 2). There were no visceromegalies.

The laboratory analysis revealed $12 \%$ eosinophilia. She did not present other laboratory changes. Stool examination detected the presence of $S$. mansoni eggs.

The anatomopathological examination showed granuloma of epithelioid macrophages involving egg with viable miracidium associated with an inflammatory infiltrate composed of lymphocytes and eosinophils, eggs in the process of degeneration with internal calcification and totally degenerated with deposition of fibrinoid material, revealing granuloma fibrosis (Figures 3, 4 and 5).

The treatment was carried out with $50 \mathrm{mg}$ praziquantel per $\mathrm{kg}$ of weight in a single dose, after which the stool parasitological examination resulted negative. There was partial cutaneous improvement, with complete response achieved after association of topical clobetasol dipropionate $0.05 \%$. 


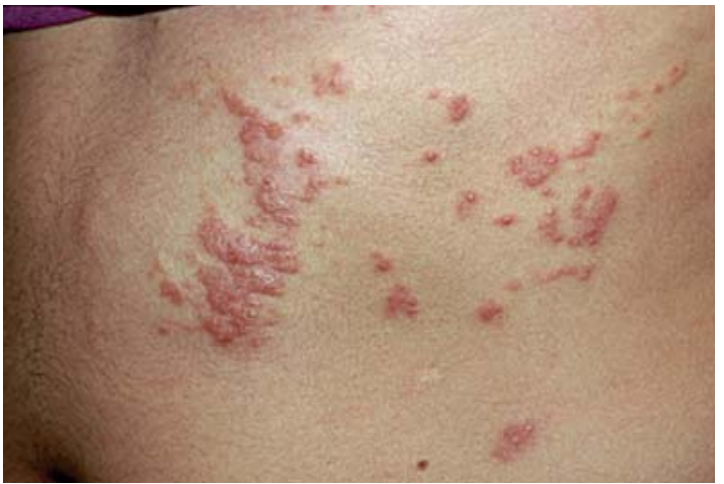

Figure 1: Round, erythematous, shiny papules of well-defined contours, measuring about $3 \mathrm{~mm}$ in diameter, confluent, some forming plaques of zosteriform aspect, affecting the abdominal region (epigastrium, mesogastrium and left upper quadrant)

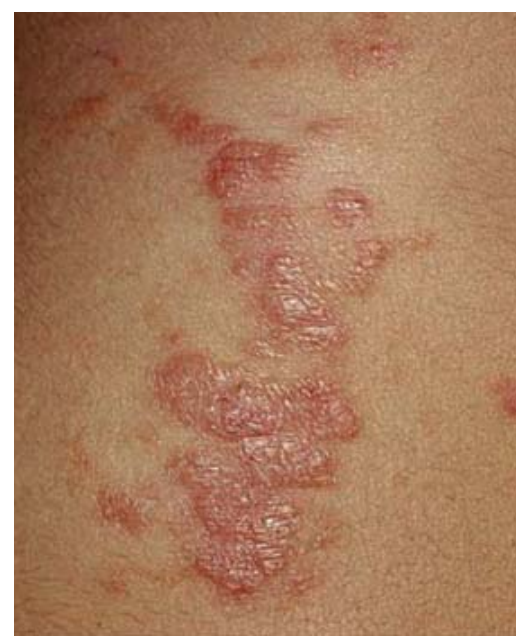

Figure 2:

Shiny erithematous papulous plaque, zoomed in, located in the mesogastrium

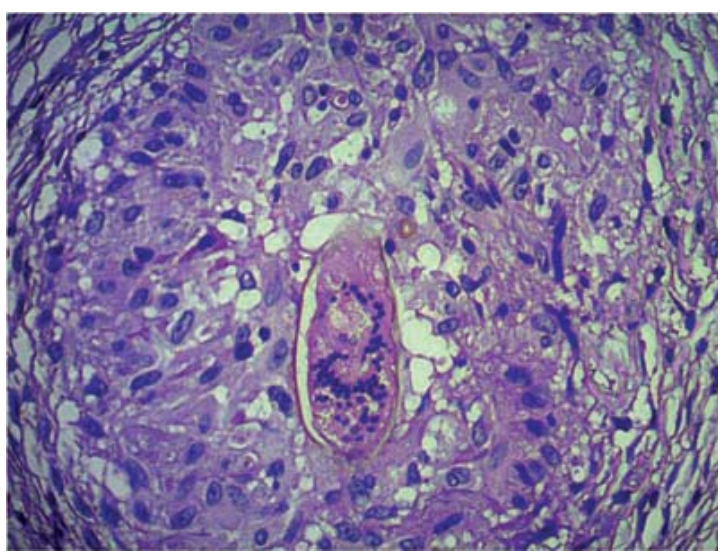

FIGURE 3: Granuloma of epithelioid macrophages involving the egg with viable miracidium associated with inflammatory infiltrate of lymphocytes and eosinophils

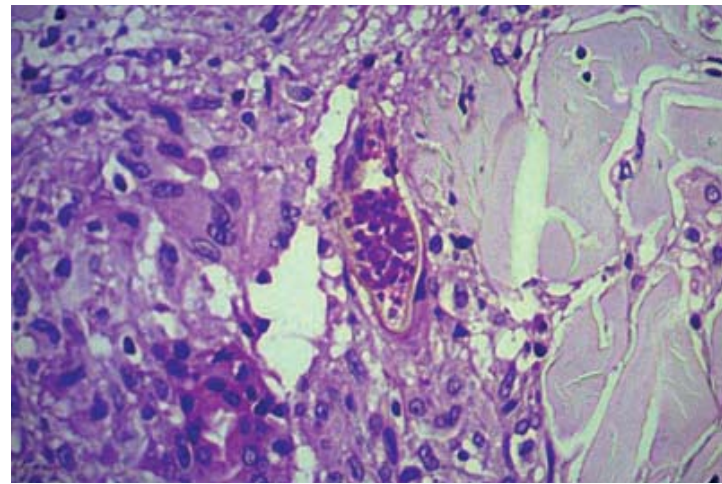

FIGURE 4: Egg with partial degeneration and internal calcification, surrounded by granuloma

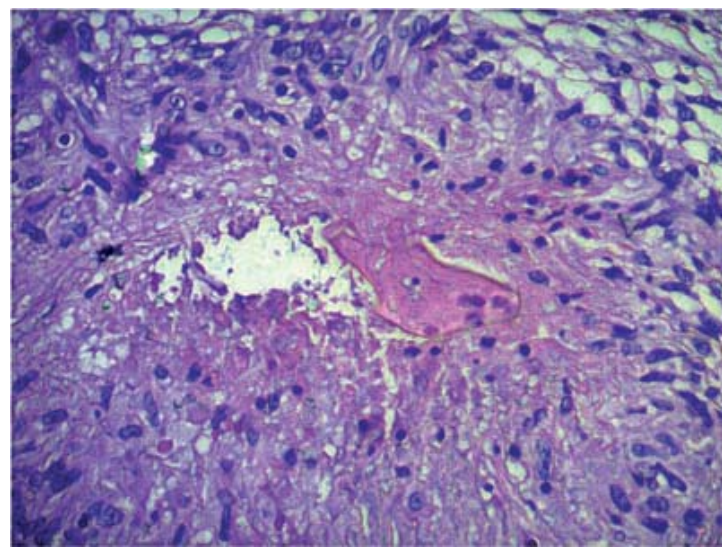

FIGURE 5: Totally degenerated egg with fibrinoid material deposition showing granuloma fibrosis.

\section{DISCUSSION}

Schistosomiasis is one the most common diseases caused by helminths. ${ }^{1}$ The states with higher prevalence are Minas Gerais, Bahia, Pernambuco, Alagoas and Sergipe. ${ }^{5}$ The life cycle of the Schistosoma is well established and deviation from its usual pattern is uncommon. When it happens, usually due to inadequate treatment of a massive initial infestation, ectopic cutaneous disorders may arise, occurring months or years after infection. ${ }^{2,6}$

The exact mechanism of deposition of Schistosoma eggs on the skin remains unknown. Faust and cols. suggested that anastomoses between venous systems are associated with migration of eggs or adult worms to ectopic sites. ${ }^{3,7}$ Many authors suggest that the parasites travel from pelvic veins, via the vertebral plexus to the spinal vessels, which would explain the zosteriform distribution, with formation of coalesced irregular plaques. ${ }^{3,6,7}$ 
Extragenital infiltrative lesions are rarer and produced by the presence of the egg on the back and on the abdomen and, in the case of recent lesions, they correspond to skin-colored or erythematous papules and, in old lesions, there appear nodules of rough, granulomatous aspect. ${ }^{8}$

The patient described was originally from Sergipe, an endemic area and presented parasitic infestation, evidenced by parasitological stool examination. She manifested dermatological lesions of recent characteristics with zosteriform distribution on the abdomen. Serum eosinophilia had similar values to other reports and dermatological manifestation was not associated with clinical findings of active visceral schistosomiasis. ${ }^{9} \quad$ This apparent lack of systemic disease in patients with cutaneous alterations was also reported by other authors. ${ }^{7,10}$

Diagnostic confirmation should be done by histopathological examination of the lesion, which has as characteristic the granuloma around the eggs. ${ }^{2}$ Eggs can also be evidenced when located on the dermis, many times in groups, associated with diffuse inflammatory infiltrate. With the progression of the disease there is disintegration of the eggs, possibly associated with necrosis. ${ }^{6}$ The clinical case reported presented all spectra of histopathological findings.

The importance of the treatment is not only about curing the disease or diminishing the parasitic load of the patients, but preventing its evolution to severe forms as well. Nowadays, praziquantel is the drug of choice, cutaneous forms included ${ }^{3}$, with a recommended single dose of $50 \mathrm{mg} / \mathrm{kg}$ for adults. ${ }^{5}$

In most published cases in the literature, ectopic cutaneous schistosomiasis lesions were milder than the one presented in the report; however, the majority was grouped in zosteriform distribution on the trunk, possibly suggesting this diagnostic possibility to dermatologists since this disorder might have been subdiagnosed, as very few cases have been described, even in areas of high endemicity. ${ }^{4}$

\section{REFERENCES}

1. Kick G, Schaller M, Korting HC. Late Cutaneous Schistosomiasis Representing an Isolated Skin Manifestation of Schistosoma mansoni Infection. Dermatology. 2000;200:144-6.

2. Lima MBA, Santos IB, França ER, d'Amorim MGM, Anna IS. Histological evolution in four cases of ectopic cutaneous mansonic schistosomiasis. An Bras Dermatol. 1995;70:31-4.

3. Tranquillini G, Hostalácio IFF, Villa RT, Silva LAG, Leitão R, Bedin V. Esquistossomose cutânea ectópica: relato de caso. Med Cutan Iber Lat Am. 2011;39:268-71.

4. Patrus 0 A. Cutaneous manifestations of Schistosomiasis mansoni. An Bras Dermatol. 1990;65:13S-17S

5. Coordenadoria de Controle de Doenças. Centro de Vigilância Epidemiológica "Prof. Alexandre Vranjac". Divisão de Doenças de Transmissão Hídrica e Alimentar. Novas estratégias para a vigilância epidemiológica da esquistossomose no estado de São Paulo. Rev Saúde Pública. 2009;43:728-30.

6. MacDonald DM, Morrison JG. Cutaneous ectopic schistosomiasis. Br Med J. 1976;2:619-20.

7. Perez EH. Ectopic cutaneous schistosomiasis. Int J Dermatol 2004; 43: 550-2.

8. El-Mofty AM, Cahill KM. Cutaneous manifestations of schistosomiasis. Dermatol Trop Ecol Geogr. 1964;30:157-61.

9. Matz H, Berger S, Gat A, Brenner S. Bilharziasis cutanea tarda: A rare presentation of schistosomiasis. J Am Acad Dermatol. 2003;49:961-2.

10. Reed LD, Theis JH. Cutaneous schistosomiasis: report of a case and review of the literature. J Am Acad Dermatol. 2000;42:678-80.

\author{
MAILING ADDRESS: \\ Lívia de Souza Mota \\ Rua Claudio Batista, S/N - Santo Antonio \\ 49060-100 - Aracaju - SE \\ Brazil \\ E-mail:liviasmota@hotmail.com
}

How to cite this article: Mota LS, Silva SF, Almeida FC, Mesquita LSU, Teixeira RDL, Soares AM. Ectopic cutaneous schistosomiasis - Case report. An Bras Dermatol. 2014;89(4):646-8. 